\title{
CIUDAD Y ESPACIOS DE REPRESENTACIÓN DEL PODER A TRAVÉS DEL NO-DO EN LA PROVINCIA DE JAÉN
}

Rafael Antonio CASUSO QUESADA

Universidad de Jaén rcasuso@ujaen.es

\section{CITY AND SPACES OF POWER REPRESENTATION'S THROUGH THE NO-DO IN THE PROVINCE OF JAÉN}

Resumen: El NO-DO es una fuente de información fundamental sobre diversos aspectos del período histórico franquista. En este caso, y desde el análisis pormenorizado de sus imágenes, extraemos algunas hipótesis, muchas veces ignoradas, sobre la dimensión urbana del mensaje visual y su paralelismo con la idea de ciudad propugnada por los ideólogos del Régimen. Los lugares de representación recreados en los noticiarios apuntan, de hecho, a una consideración "orgánica" del espacio urbano en la que encaja, con un protagonismo rector, el centro de la ciudad, complementado con unas extremidades funcionales que constituyen las nuevas barriadas y sus diversos servicios. Las imágenes del NO-DO nos hacen testigos de la lenta, pero progresiva conformación de este proceso.

Abstract: NO-DO is an essential source about different aspects in Franco Regime. In this case and from the detailed analysis of its images, we deduce some hypothesis, most of the times disregarded, about town planning dimension and the visual message advocated by the Francoism`s ideologists. The representation places recreated in the news broadcast point to an "organic" consideration of the town planning in which fits in the city center, concluded with other spaces that constitute the new neighborhoods and their different services. NO-DO images are witness to this conformation process.

Palabras clave: NO-DO. Ciudad. Urbanismo. Jaén. Cine. Franquismo City. Townplanning. Jaen. Cinema. Franco Regime 
La puesta en marcha del NO-DO a partir de la publicación de una orden en el Boletín Oficial del Estado el 22 de diciembre de 1942 desencadena la visualización de una serie de resortes ideológicos tendentes a la consolidación pública y general del régimen de Franco. La proyección obligatoria en los cines de toda España de estos noticiarios y documentales estaba auspiciada, de hecho, por la Vicesecretaría de Educación Popular a través de un organigrama administrativo ligado directamente a las Delegaciones Nacionales de Propaganda y de Prensa, controladas por la Falange: "La cinematografía y los noticiarios filmados con un sistema de censura y control similar en sus grandes líneas al de los otros campos" (Bermejo Sánchez, 1991:83). La instrumentalización oficial de esta serie de discursos, en los que subyace un fuerte contenido político, se lleva a cabo desde el mismo inicio de las proyecciones a partir del año 1943. Sin embargo, no faltaron hasta entonces algunos intentos por ejecutar esa idea de control informativo, como el llevado a cabo a finales de 1941 por la Compañía Española de Propaganda, Industria y Cinematografía S.A. (CEPICSA), consistente en distribuir por las plazas de las ciudades españolas más pobladas (en el caso de Jaén, la capital, junto con Linares y Andújar), las denominadas "Columnas Cineparlantes y Publisonoras", complementadas con la distribución de aparatos de "Radio Publisonora" para instalar en trenes, aviones, autobuses o taxis ${ }^{1}$.

El primer noticiario realizado por NO-DO se llevó a cabo el 4 de enero de 1943 y se estrenó en los cines Cervantes e Iris de la capital, como recogían con alborozo las páginas del Diario Jaén, insistiendo en el alarde técnico de la cinematografía española:

"NO-DO en sí, con ser muchos sus aciertos, tiene uno indiscutible y magnífico. El de conseguir mover con irresistible simpatía hacia el film que vemos, nuestros más puros sentimientos patrióticos, hasta el extremo de hacer que nuestro pecho se llene de noble orgullo español"2.

Su extrapolación a los cines evidenciaba que el control y la centralización de los servicios de información y propaganda del Estado necesitaban llegar al mayor número de personas, pero además su dimensión urbana, tal y como vamos a analizar a lo largo de este estudio, se va a reflejar en el propio contenido de los noticiarios. Nos referimos al frecuente recurso en los rodajes a señalar determinados "hitos" de la ciudad, convertidos en espacios de representación del poder (plazas, balcones, avenidas o nuevas barriadas), y a subrayarlos con una cuidada teatralidad por medio del empleo de la arquitectura efímera, o de las diversas tipologías arquitectónicas cuya variedad sería la demostración del progreso del país:

"En este apartado queremos hacer hincapié en la importancia que la ideología franquista dio a la concepción del espacio como componente ritual de sus actos... Así, a instancias de Eugenio D’Ors (Director de la Jefatura Nacional de Bellas Artes) se creará en 1938 la Comisión de Estilo en las conmemoraciones de la Patria. Dicha comisión se vincularía poco después con el Departamento de Plástica para dar origen al Departamento de Ceremonial y Plástica, dependiente de la Delegación Nacional de Prensa y Propaganda. Su cometido no era otro

\footnotetext{
1 El fracaso de la idea se debió a muchos factores, especialmente de carácter técnico, destacando también el componente empresarial de procedencia mayoritariamente privada, a pesar de que el consejo de administración de CEPICSA se ponía al servicio del Gobierno Civil y la Jefatura Provincial del Movimiento en cada provincia: "El sueño de un control ideológico que iba más allá de lo realmente verosímil, como se proponía en las columnas cineparlantes y publisonoras, quedaría en los anales de la utopía futurista del Franquismo" (Casuso, 2016: 78). 2 Diario Jaén, 5 de enero de 1943, s/p.
} 


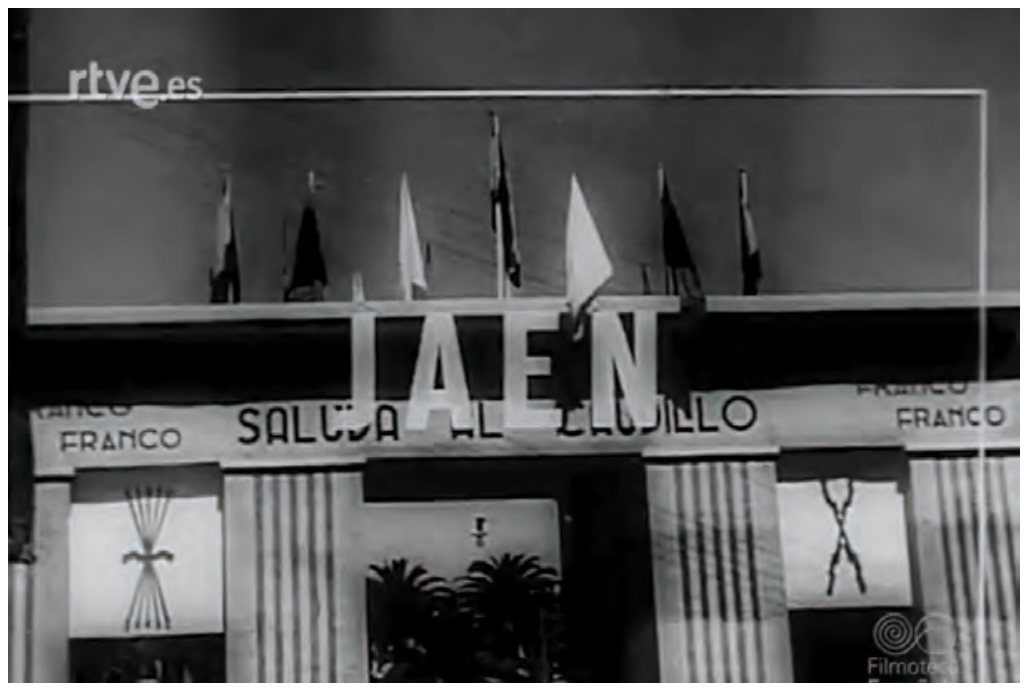

Imagen 1. Estructura triunfal para recibir al Caudillo en Jaén (noticiario 21B, 1943).

que la construcción de monumentos y la organización de conmemoraciones, desfiles y actos patrióticos" (Tranche y Sánchez-Biosca, 2006: 224-225)³.

En el presente estudio se han seleccionado una serie de noticiarios, especialmente aquellos que tuvieron mayor contenido político y significación urbana. Así, la primera visita de Franco a la provincia de Jaén narrada por el NO-DO fue la realizada en 1943 y está registrada en el noticiario 21B, con motivo de su asistencia a una concentración de Falange Española Tradicionalista y de las JONS en la capital. Se inicia con un plano fijo de la estructura arquitectónica efímera que, a modo de pórtico, introduce en la narración. Sorprende su magnificencia y a la vez su sencillez, principios que la hacen deudora de la estética racionalista italiana, aún al uso en aquel país en su deriva mussoliniana y de claro significado fascista para la fecha en que sucede el acto. Cuatro sólidos pilares a la misma altura sostienen un gran dintel en cuya parte central dice "Saluda a Franco" y en ambos laterales se repite por dos veces el lema "Franco, Franco" (imagen 1). En los huecos laterales se disponen dos símbolos político-ideológicos bien significativos: el escudo de Falange, con el yugo y las flechas, y la cruz de Borgoña, identificativa de los carlistas. De esta manera el espectador entra de lleno en la gran explanada donde lucen uniformadas, y bien formadas, las huestes provinciales de la F.E.T. y de las J.O.N.S. Un sencillo pódium, menos grandioso, pero de estética también funcionalista, con la típica baranda de tubos paralelos, sirve al líder de balcón improvisado para arengar a la tropa. Aparecen entonces, en un intencionado avance narrativo desde lo general a lo particular, los primeros planos de rostros de personas concretas, chicos con boina que saludan al modo fascista y vitorean al Generalísimo de la tropa. En este caso Franco viste de militar y luce la boina carlista.

Como espacio de representación del poder esta gran explanada se ubica en una zona sin urbanizar por la carretera de Granada, de donde procedía la comitiva del Caudillo, arrancando desde allí un multitudinario desfile a través de la avenida del Generalísimo, actual paseo de la Estación. La entrada al centro se produce, de hecho, por la calle Roldán y Marín,

3 A nivel general la idea está esbozada en el capítulo "Los espacios de representación: escenografías, arquitectura y memoria" de la conocida monografía sobre el NO-DO. El tiempo y la memoria, pero se recrea en el análisis de aspectos estéticos, composiciones rituales o puesta en escena, más que en el análisis de las ubicaciones urbanas y la ocupación del espacio. 


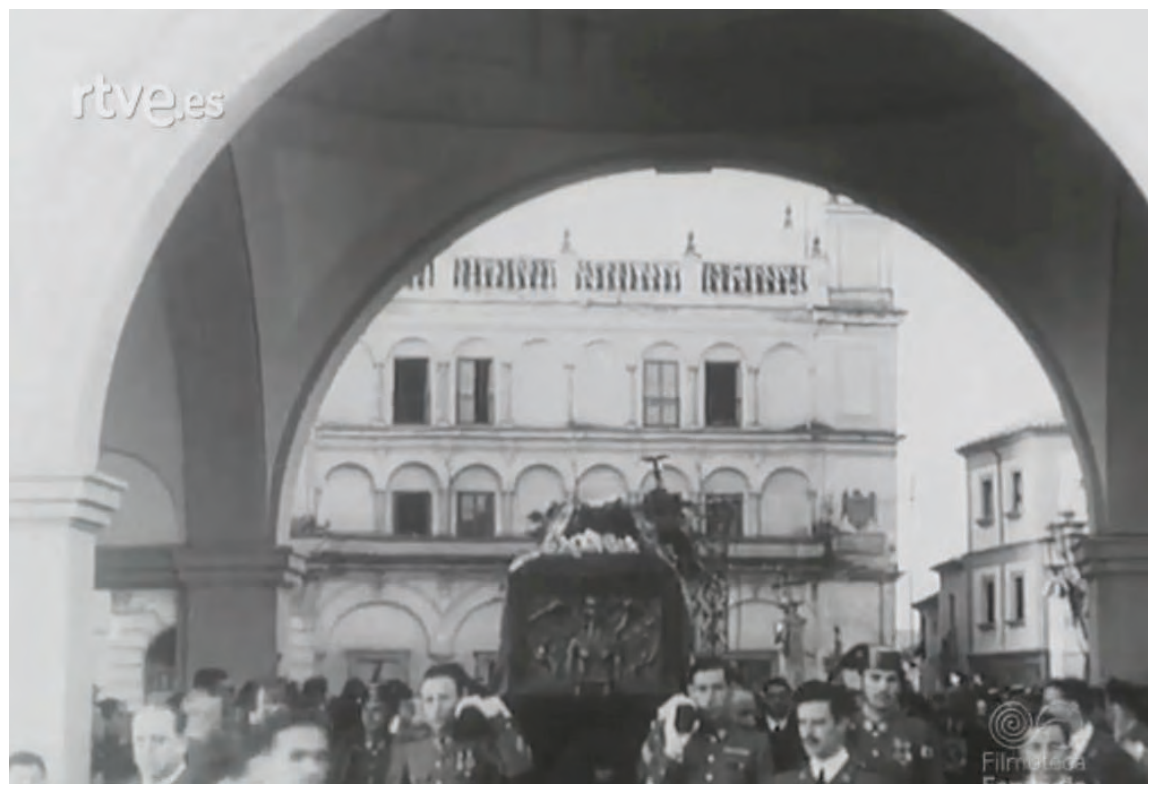

Imagen 2.- Comitiva del féretro del Capitán Cortés en Andújar (noticiario 122-B, 1945).

hasta llegar a la plaza de José Antonio, actual de la Constitución. La cámara entonces ofrece al espectador con detalle el paso de las diferentes secciones deportivas de la Falange mostrando a la población las bondades del ejercicio físico bien encauzado: montañismo, fútbol, ciclismo, atletismo o baloncesto, representados por fornidos atletas que portan carteles y lucen las prendas de las diversas actividades. El recorrido está adornado con una sucesión de pilares sencillos que sostienen banderas en una nueva demostración de arquitectura efímera. En la plaza de José Antonio, elegida posiblemente por la simbología del nombre, dado el cometido político de la concentración, se eleva un sencillo pódium donde espera el Caudillo a los participantes en el desfile, a quienes saluda al modo fascista, brazo en alto. De fondo aparece una multitud enardecida que es contenida por fuerzas de la Guardia Civil, imagen paradójica del fomento del ejercicio en los duros años de la penuria y del hambre.

El tono político y la visualización de las noticias van modificándose una vez finalizada la segunda guerra mundial, con la derrota de las potencias del Eje. La simbología fascista y la significación de los actos comienzan a matizarse de manera paulatina, no sólo en lo que respecta a cambios gubernamentales, dando entrada el dictador a sectores monárquicos homologables al ámbito europeo occidental, sino también a un sutil revisionismo histórico. Hitos ideológicos de especial relevancia nacional tras la finalización de la Guerra Civil, como el asedio al Santuario de la Virgen de la Cabeza en Andújar, comienzan a ser valorados de manera diferente. Lo que en 1939 constituía para el Régimen la propaganda del inicio de la reconstrucción del Estado con la visita de Franco a las ruinas resultantes del asedio republicano, en 1945 cuando quedaba inaugurado oficialmente el nuevo edificio, el Caudillo delegaba su representación en la figura del Capitán General de la Guardia Civil, Camilo Alonso Vega. Ello a pesar de que el acto coincidió con el traslado de los restos mortales de los capitanes Cortés y Haya, los defensores del Santuario, desde el emplazamiento provisional en la iglesia de Santa María en Andújar hasta el Santuario. A este hecho el NO-DO le dedicaría el noticiario 122-B, destacando el recorrido del cortejo fúnebre por la plaza del Ayuntamiento, atravesando el arco del flamante edificio de Correos y Telégrafos, erigido por la Dirección General de Regiones Devastadas gracias a la intervención de los arquitectos Francisco Prieto Moreno y Ramón Pajares Pardo (imagen 2). 
Tanto en éste, como en el anterior noticiario, hemos observado una especial predisposición por localizar en lugares emblemáticos de la ciudad los actos relevantes publicitados, como han sido la antigua plaza de José Antonio en Jaén o la del Mercado en Andújar. Esto tiene una relación inevitable con la propia idea de la ciudad que subyace en la teoría urbana del Franquismo, como se deduce de las palabras de Pedro Bidagor, director técnico de la Comisaría de Urbanismo de Madrid en 1945 y futuro Jefe Nacional de Urbanismo

“[...] una ciudad bien ordenada dispone en la localización más ventajosa los centros urbanos y representativos, constituyendo la cabeza de la ciudad: los barrios residenciales y urbanos se sitúan en íntimo contacto con el centro y se procura que las zonas modestas, por su fealdad, incomodidad o insalubridad, tengan un emplazamiento separado, desde luego, lo más alejado posible de los centros cívicos y representativos. Es decir, que la ciudad, como un ser vivo, se organiza con una cabeza rectora, directora y representativa, un cuerpo que contiene la vida propia urbana y unas extremidades funcionales" (Ureña, 1979: 97-98).

El sentido organicista de la ciudad se fue ejecutando en la provincia por organismos como la Dirección General de Regiones Devastadas, especialmente en las localidades más dañadas por la guerra como fueron las del frente entre Lopera y Porcuna, cuyas reformas urbanas se aplicaron a partir de 1943 por el arquitecto del citado organismo, Ramón Pajares Pardo (Casuso, 2012: 6). En cualquier caso, el sentido de la "capitalidad" otorgada al centro urbano, requería obligatoriamente del concepto de funcionalidad de las extremidades, del extrarradio, como se evidencia en el noticiario 364-A, dedicado a la inauguración de la Estación de Autobuses en el año 1949, promovida por la compañía privada "Auto Estaciones". La segunda vez que aparece la capital de Jaén en el NO-DO lo es para visualizar una nueva tipología arquitectónica, característica de las innovaciones técnicas y viarias del siglo $X X$, en la que la ciudad fue pionera a nivel nacional ${ }^{5}$. Llama poderosamente la atención que la introducción a la noticia se haga dentro del capítulo "Actualidad Nacional", con una carátula casi futurista en la que aparece el dibujo de una ciudad moderna con viaductos, rascacielos, aviones y autobuses de dos plantas (imagen 3).

Está germinando una nueva ciudad, la del automóvil, símbolo de la modernidad, que necesita de nuevas construcciones para articular otras necesidades, como nos traslada la narración del noticiario:

"La ciudad de Jaén es objeto de cuidadosas atenciones por su Ayuntamiento, que en terrenos cedidos por la Corporación Municipal, y en la zona del ensanche, ha visto inaugurar una nueva estación de autobuses que ocupa una superficie de 9.000 metros cuadrados y que recoge 35 líneas de viajeros. La construcción ha costado más de seis millones de pesetas. Al acto inaugural asistieron, con el Director General de Ferrocarriles y el Obispo de la Diócesis, las principales

\footnotetext{
4 La interpretación biológica de la ciudad por parte de Pedro Bidagor lo evidencia el arquitecto y urbanista Fernando Terán en la célebre entrevista que le realizó en 1983: http://www.raco.cat/index.php/QuadernsArquitecturaUrbanisme/article/viewFile/199093/298120

5 "El verdadero salto de escala que se produce en las ciudades, durante el primer tercio del siglo XX, tiene que ver con las infraestructuras del transporte y más concretamente con las estaciones de autobuses. La primera estación de autobuses puesta en servicio en Andalucía corresponde a la de Sevilla, proyectada por Rodrigo Medina Benjumea y construida entre 1938 y 1944. La ciudad de Jaén inició las gestiones para dotarse de una estación de autobuses en 1933 y a la postre fue la segunda capital andaluza en disponer de una estación" (Quesada y Casuso, 2006: 26-27).
} 


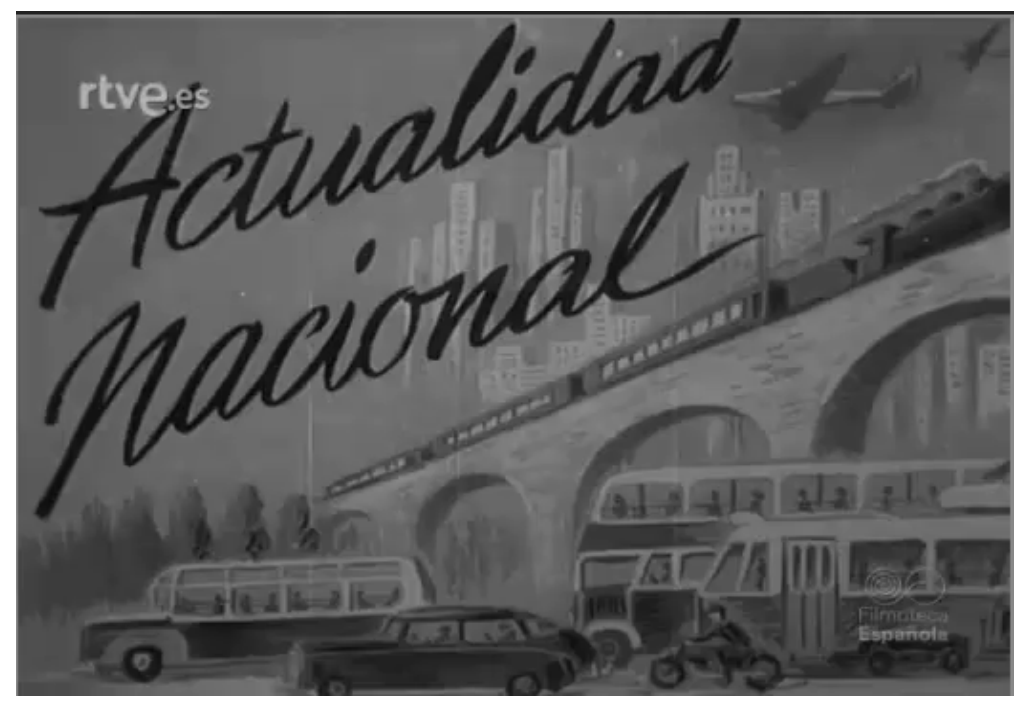

Imagen 3.- Carátula de inicio del noticiario 364-A (1949).

autoridades locales y el Ingeniero Director de las obras. La nueva estación facilita el desahogo a todos los servicios centrados en la misma".

Se recrea también la imagen en un mosaico dispuesto en el vestíbulo que expone la Red Provincial de Carreteras. Jaén capital, con un dibujo de la Catedral, aparece con una centralidad relevante, "[...] por su cualidad de cabeza de una provincia rica"6, apareciendo también un dibujo del Santuario de la Virgen de la Cabeza en Andújar, el guiño ideológico imprescindible, y la torres del palacio de los Condes de Guadiana en Úbeda, la dimensión turística inevitable en un edificio dedicado al transporte.

El concepto de "centralidad", empleado en sentido territorial y político por el reportaje del Diario Jaén sobre la inauguración de la Estación de Autobuses, se acentúa desde el punto de vista urbano en los noticiarios del NO-DO con el recurso al balcón de edificios representativos como lugar "capital" de la ciudad, plataforma de proclamación de los mensajes ideológicos ${ }^{7}$. La segunda visita de Franco a la provincia de Jaén se produce en 1951 y se recoge en los noticiarios 441-A y B. El primero de ellos se denomina "La obra de Franco" y describe su visita a Andújar, donde la comitiva accede a una abarrotada plaza del Mercado, deteniéndose el célebre Rolls Royce a las puertas del Ayuntamiento desde donde el Caudillo accederá a su balcón principal. La localidad era de especial relevancia en el imaginario propagandística del Régimen, pero hay que destacar la vestimenta de Franco, quien aparece de civil, mientras que el alcalde lo hace de falangista. Es posible que este tipo de detalles mostrados por los cines de toda España, se deba a la necesidad de visualizar en actos civiles una nueva imagen, más moderna y menos militarista, complaciente con los países occidentales de los que, curiosamente, el NO-DO cada vez introduce más información en sus noticiarios. El especial cuidado con el que el Régimen va modulando sus mensajes se observa en el recurso a la simbología que transmiten las imágenes de los noticiarios. Si, por un lado,

6 Diario Jaén, 13 de diciembre de 1949, s/p.

7 Monografías locales sobre el NO-DO relativamente recientes ignoran, por encima de la claridad y profundidad de sus análisis, la dimensión urbana de los mensajes ideológicos de sus mensajes. Es el caso de la de Huelva, cuyo estudio se ciñe a cinco apartados: Franco, enclaves ideológicos, instituciones, desarrollo del país, religiosidad y divertimento (Navarrete, 2003: 51-55) 
interesa acentuar las aportaciones modernas de una España nueva que supera la destrucción de la Guerra Civil, por otro, casi siempre aparece la tradición histórica como base y sustento de la misma. En esa misma visita de 1951 el noticiario número 441B se inicia, por ejemplo, con un primer plano de los portadores del pendón de las Navas de Tolosa y la cruz, la mejor forma en la que Vilches expresa su adhesión al Jefe del Estado. Esto es independiente de que la mayor parte del metraje se dedique a exponer el estado de las obras del pantano de Guadalén en un recorrido en el que Franco está acompañado por las autoridades civiles y militares, así como por los operarios de la obra. El paisaje serrano contrasta entonces con la siguiente secuencia, introductoria a la visita de Franco a Baeza, en el que aparece una loma de olivos y el cartel de carreteras que da acceso a la ciudad. De nuevo el contraste entre la España industrial y rural que los noticiarios del NODO no dejan pasar por alto a sus espectadores, como muestra de la diversidad paisajística y económica del nuevo Estado.

La importancia del balcón como espacio representativo, especialmente el del ayuntamiento, al que se asoma en sus visitas a Andújar y a Baeza, también adquiere protagonismo en Jaén, como se observa en este noticiario, aunque por su dimensión capitalina y respetando el riguroso orden jerárquico, en este caso emplea el del palacio de la Diputación Provincial (imagen 4) Franco llega hasta él a través de una Carrera abarrotada de jiennenses y con una amplia comitiva de vehículos. Su discurso, en otro orden de cosas, trasciende el ámbito de lo local:

"Su Excelencia alude en sus manifestaciones y discursos el estudio efectuado por la Secretaría de Ordenación Económico Social sobre el paro endémico, consecuencia del monocultivo del olivo, y expresa cómo la provincia verá realizado su programa de renovación y de mejora por la fe, la constancia, el trabajo y la hermandad".

Normalmente estos balcones suelen estar decorados con tapices que representan el escudo nacional y el de la localidad o la provincia, como es el caso, pero aquí llama la atención

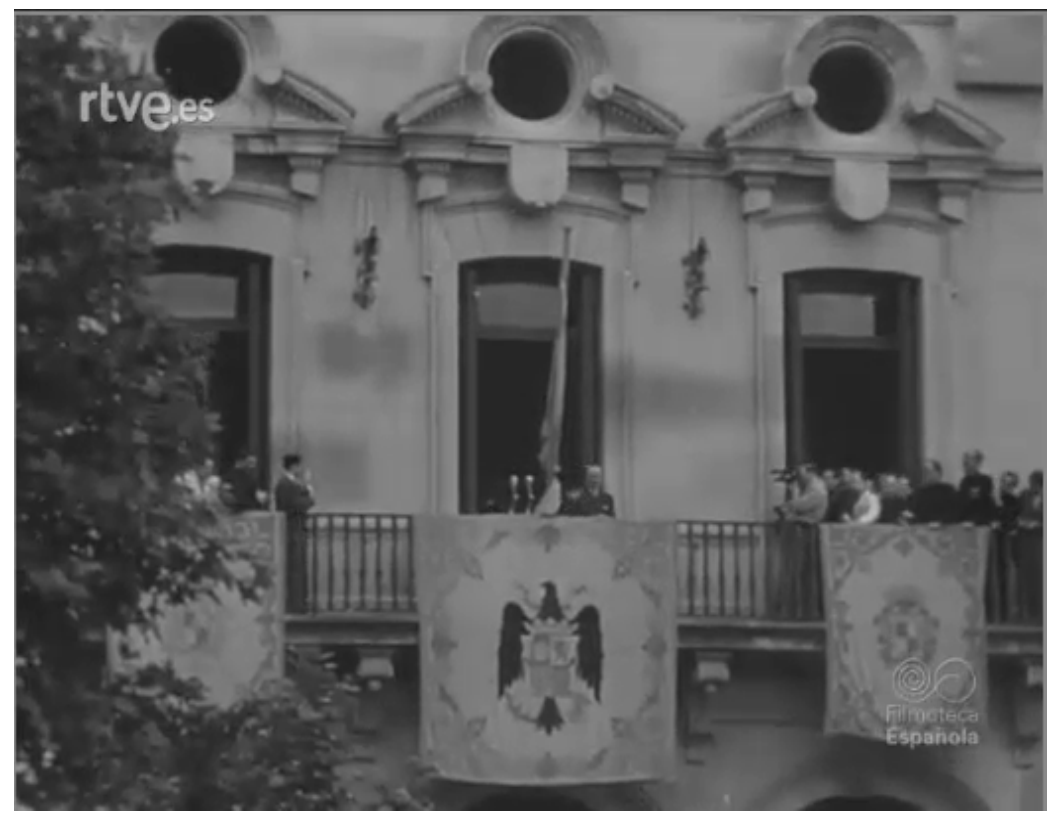

Imagen 4. Franco saluda desde el balcón de la Diputación Provincial en Jaén (noticiario 441B, 1951). 
el cambio de gestualidad en dos imágenes significativas. La primera se refiere a la manera de saludar, siendo sustituido el saludo fascista por un levantamiento más vertical del brazo, y la segunda a la forma en la que se desplaza a la Catedral desde el Palacio Provincial, caminando a través de la calle Campanas y en contacto muy directo con la gente. Está claro que el NO-DO nos quiere ofrecer una faceta del dictador más cercana al pueblo, siendo agasajado por un grupo de pastiras que arrojan pétalos de rosas a su paso. No en vano, y seguidamente, el obispo le espera a la entrada de la Catedral con el palio correspondiente para iniciar la visita al templo. No existe durante este viaje de 1951 ningún recurso a la arquitectura efímera. En la localidad de Porcuna, también hay una componente religiosa en el recibimiento al Caudillo con una visita a la iglesia de la Asunción.

La centralidad de las plazas es fundamental en este tipo de actos y en el caso de la ciudad de Jaén adquiere especial significado la de Santa María, donde se ubican la Catedral, el Ayuntamiento, el Obispado y el Banco de España. En el noticiario 830A del año 1958 vuelve a adquirir protagonismo con motivo de una concentración falangista presidida por el ministro Secretario General del Movimiento, José Solís. Aparece ocupada por 20.000 personas según el narrador y desde el punto de vista ideológico resulta muy interesante constatar el afán propagandístico del noticiario, en este caso utilizando como motivo los favorables resultados del Plan Jaén tras sus primeros cinco años de aplicación y que son elogiados por el Gobernador Civil, Felipe Arche. El ministro es el que impone las medallas de reconocimiento a los camaradas, a los que el narrador describe como miembros de la "vieja guardia", aunque su referencia al pasado contrasta con la apuesta de futuro que se observa en el desfile de carrozas a lo largo de la Carrera. Es llevado a cabo por las empresas subvencionadas por el Plan Jaén a modo de demostración ante la comitiva política de los avances conseguidos, apareciendo vehículos adornados con entramados eléctricos, tuercas gigantes, mineros picando en vivo, envases de aceite o productos cárnicos, a veces aderezados con mujeres ataviadas con trajes típicos. El inexorable paso del tiempo resulta evidente, incluso para el Régimen, si comparamos la multitud falangista congregada en la plaza, política y antigua, con esta otra, productiva y joven, que se nos ofrece en la Carrera. Como muestra de arquitectura efímera sólo aparece una gran estructura adintelada en la plaza de San Francisco, al inicio de la calle Campanas y ocupando toda su anchura, coronada con una especie de frontón partido y con un lema en el dintel que apenas si se distingue en el lejano enfoque de la cámara.

El contrapunto urbano al exceso de la centralidad la encontramos en el extrarradio, las afueras de la ciudad, allí donde comienzan a erigirse las barriadas más humildes. El tratamiento del proceso en los noticiarios del NO-DO es bien escaso y cuando lo hace se efectúa desde un criterio paternalista, a pesar de que en las ciudades de la provincia se constata la construcción de barriadas periféricas en los más inmediatos años de la posguerra (Casuso, 2012: 5), como es el caso de la barriada de Fátima en Jódar (Francisco López Rivera, 1941), la del Matadero en Andújar (Pedro Rivas Ruiz, 1948) o la de Peñamefécit en Jaén capital (Juan Piqueras Menéndez, 1950). Para encontrar alguna referencia al proceso hay que trasladarse al año 1960 en el noticiario 893-B, cuyo título "Humor y caridad" da idea de la manera en la que se trata la promoción de viviendas sociales. Consiste en una campaña de captación de fondos denominada "Operación escoba" mediante la cual famosos actores, actrices y toreros de la época recogen el dinero que un público entusiasta lanza al suelo en un sitio tan representativo como la plaza de Santa María de Jaén, y bajo la atenta mirada del Gobernador Civil, Felipe Arche. El dinero recaudado, que superó según el noticiario el millón y medio de pesetas, fue destinado a la financiación de la primera promoción de "viviendas para los humildes" que se iba a realizar en el Polígono del Valle, y cuyas primeras 10 casas fueron entregadas a sus moradores por el actor José Isbert ${ }^{8}$. En palabras del narra-

8 Estos “divertimentos", independientemente de su mayor o menor implicación urbanística, escondían sublimi- 


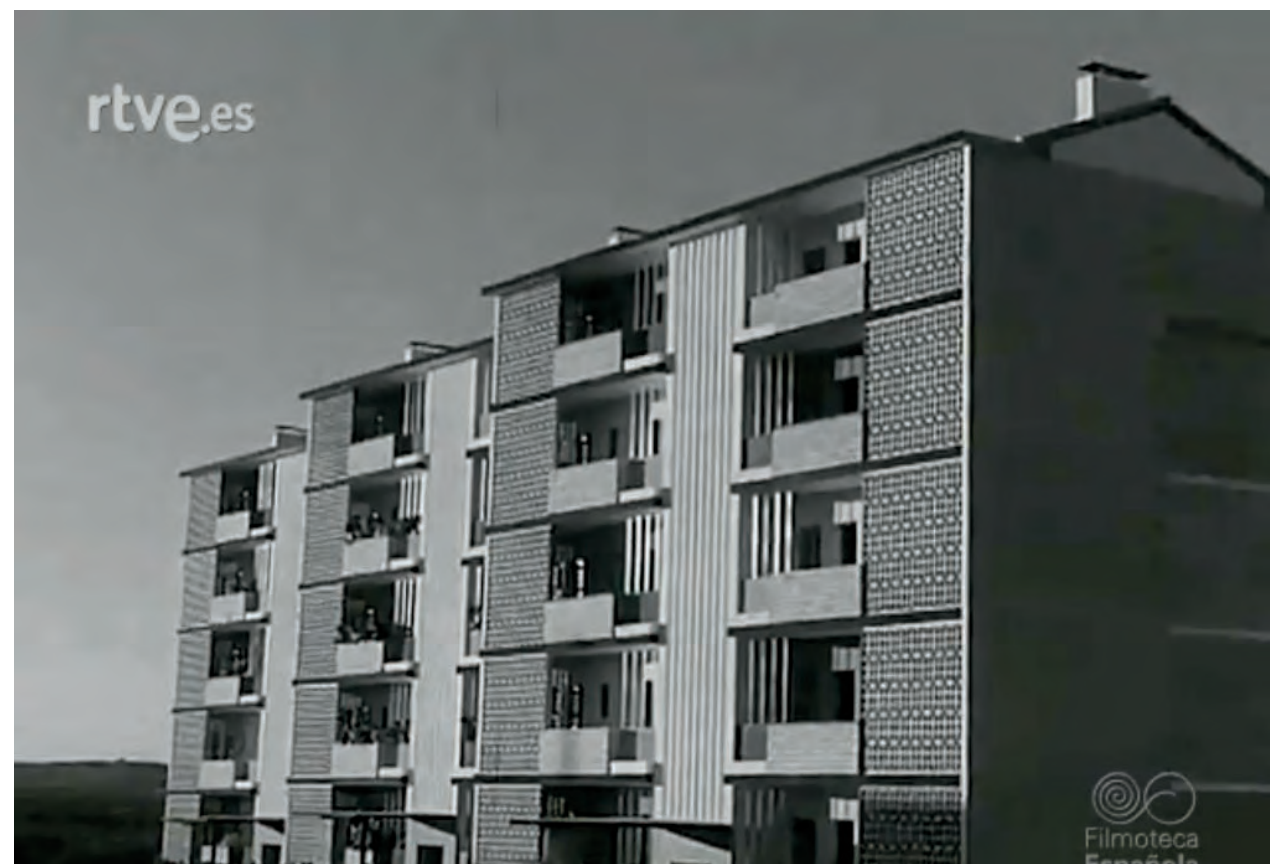

Imagen 5. Viviendas de la “Operación escoba” en Jaén (noticiario 893-B, 1960).

dor, "contribuyendo a suministrar pisos a las personas necesitadas y a resolver el acuciante problema del alojamiento" (imagen 5). Este acto se complementa con imágenes del exterior del conjunto de pisos, especialmente destinado a personas necesitadas y humildes, como nos narra el locutor, construidos junto a lo que iba a ser el Centro de Formación Profesional Acelerada, en la misma carretera de Madrid, un nuevo eje del Jaén moderno que progresa a partir de la caridad y la solidaridad social ${ }^{9}$.

Paulatinamente se iba ejecutando en nuestras ciudades el programa urbano de la Falange que, aplicado a la vivienda social, tuvo como punto de partida un proyecto de los arquitectos Vicente Baztán y Gaspar Blein en Andújar en 1940:

"El concepto de nuevas barriadas ha sufrido una honda transformación como consecuencia de la sustitución de los conceptos democráticos de la vida por los de autoridad, jerarquía y disciplina, indispensable a la misión histórica de España, que caracterizan el glorioso Movimiento Nacional. Lo liberal ha sido desplazado por lo orgánico y esto forzosamente ha de reflejarse en aspectos sociales tan importantes como la ciudad y la vivienda. Así ocurre que en

nalmente mensajes políticos: "En este sentido, uno de los máximos logros que puede apuntarse NO-DO es la de su capacidad para despertar la aquiescencia de los espectadores mediante la utilización y articulación de una red simbólica fácilmente reconocible por la población al encajar en su mundo cotidiano[...] Con ello, presentándose con los tintes de la neutralidad informativa, de la crónica inocua de una actualidad rutinaria e intrascendente, el mensaje de NO-DO conseguía una efectividad mayor a la hora de difundir el mensaje deseado por la dictadura que cualquier film de intencionalidad política" (Fandiño, 2009: 42-43).

9 El caso de las viviendas protegidas de Jaén es diferente, a pesar de que su diseño se anticipa a 1940, socialmente porque están dirigidas a funcionarios públicos (Ayuntamiento, Diputación y Organización Sindical), y urbanísticamente no tienen un carácter periférico (están ligadas al eje preestablecido por el Paseo de la Estación desde principios del siglo XX). El polígono del Valle, por el contrario, formaba parte de la expansión norte adelantada en el Plan de Ordenación Urbana de 1952. 


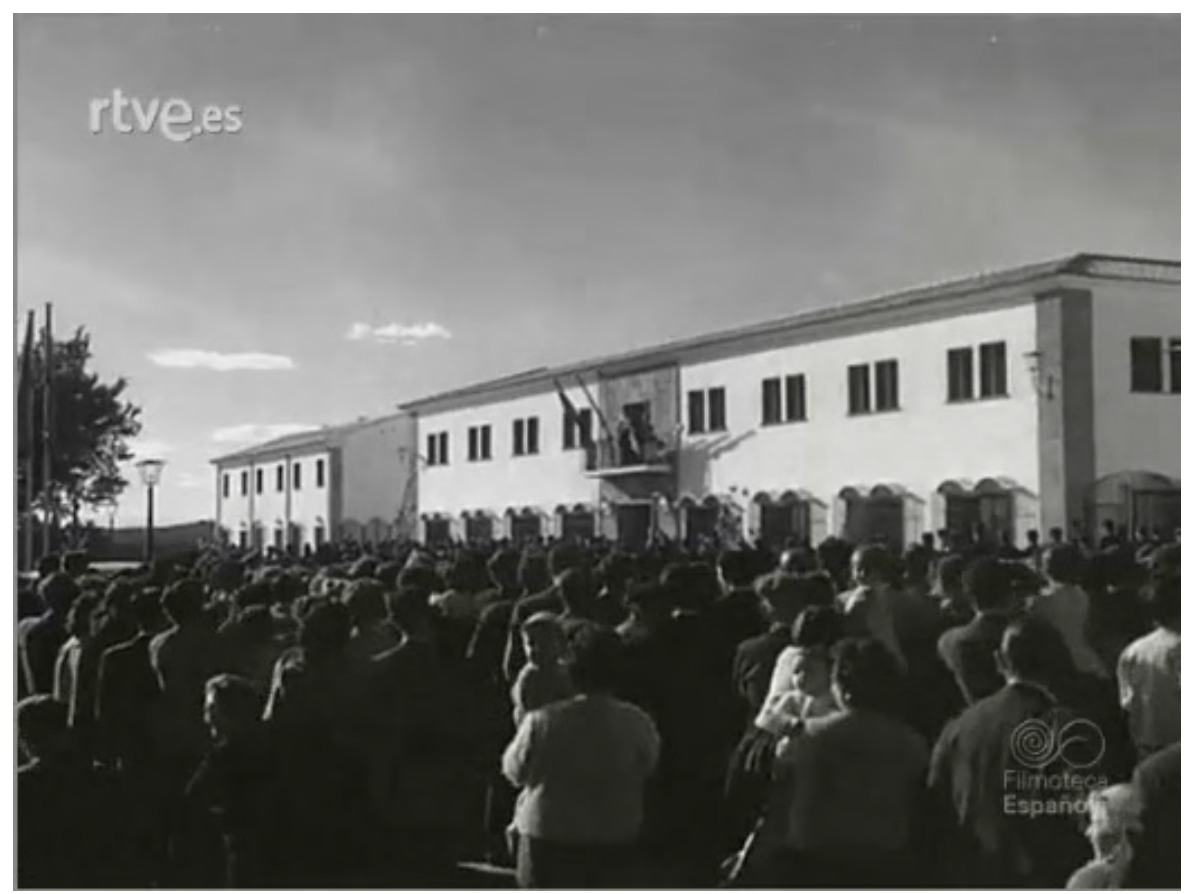

Imagen 6. Franco saluda desde el balcón del Ayuntamiento de La Carolina (noticiario 956-B, 1961).

buena teoría urbanística no puede ya admitirse el crecimiento de la ciudad por acumulación ilimitada, y casi siempre caótica, de viviendas agregadas por la iniciativa particular a los antiguos núcleos de vida que acaban por descomponer su funcionamiento, ni tampoco por funestas casas baratas de un solo tipo de clases sociales, fomentadoras de la lucha de clases, sino por unidades orgánicas o núcleos completos con sus centros cívicos, escuelas, lugares de esparcimiento, etc., todo relacionado con los lugares de trabajo que permitan un desarrollo económico y ordenado" ${ }^{10}$.

La siguiente visita del Caudillo de la que existe constancia en el NO-DO es la efectuada en 1961, diez años después de su primera visita oficial, y está dedicada a exaltar las bondades del Plan Jaén. Dada la importancia del acontecimiento, para ello se elaboraron los noticiarios 956-A y 956-B, ambos con fecha de uno de mayo, que se inician con la entrada de Franco en la provincia por La Carolina. Allí se utiliza de nuevo el balcón de la Casa Consistorial para dirigirse a las masas enfervorizadas presentando al Movimiento Nacional como la plataforma que redime a la provincia de la antigua política, causante de la miseria, la decadencia y el secular abandono de esta tierra (imagen 6).

A diferencia del noticiario de 1958 donde también se exaltaba la puesta en funcionamiento del Plan Jaén, éste es mucho más completo, pues se realiza un recorrido por todo el territorio y se hace hincapié especialmente en el despegue industrial. Hay que tener en cuenta que al inicio de los sesenta el célebre Plan de Estabilización ya estaba puesto en marcha y se necesitaba publicitar el proceso por el que España abandonaba el sistema económico de la autarquía, para abrirse a un modelo de liberalización e internacionalización. No en vano

10 Archivo Municipal de Andújar. Documentos varios, "Proyecto de casas unifamiliares para obreros en la avenida de la Plaza de Toros". Madrid, 1940. 
acompaña a Franco en esta visita el ministro Luis Carrero Blanco, artífice del cambio de gobierno que introdujo a los "tecnócratas", expertos economistas, como López Rodó, sin vinculación política arraigada en el Régimen y ligados al Opus Dei. También explica esto la variedad de tipologías arquitectónicas que nos presenta el noticiario, símbolo del progreso de la provincia. Desde luego las industriales, como el embalse de doña Aldonza, cerca de Villacarrillo, expuesto no sólo como punto de origen de los riegos de las vegas altas de Jaén por parte de la Confederación Hidrográfica del Guadalquivir, sino como moderna central hidroeléctrica cuyo salto iba a generar la potencia necesaria para el desarrollo industrial. Por supuesto las construcciones relacionadas con la educación, el otro sostén del progreso, incidiendo en su vertiente formativa de técnicos con capacidad para incorporarse al mercado de trabajo que ofrecen los nuevos servicios. Eso explica la visita de Franco a las Escuelas Profesionales de la Sagrada Familia en Úbeda, destacando de nuevo su vestimenta civil.

El resto del noticiario consiste en incidir en estos aspectos, pues aparece inaugurando algunos poblados de colonización, como el de Campillo del Río, donde se observa la apuesta del Instituto Nacional de Colonización por la vivienda unifamiliar agraria, cuyos títulos de propiedad entrega a los nuevos colonos. Es significativa la forma en que el narrador utiliza el término de Reforma Agraria para referirse a estos hechos, arrebatando su asociación tradicional a la ideología socialista. Este acercamiento tangencial hacia principios de contenido social no era nuevo para una ideología como la Falange, y de hecho también acompaña a Franco el ministro Secretario General del Movimiento, José Solís, pero existe un interés por parte del noticiario en alabar la alta ocupación obrera promovida por el Plan Jaén, como una estrategia política. Así, los siguientes planos muestran la gran variedad productiva del centro industrial que se pretende potenciar en Linares por medio de empresas como Santana, donde se fabrican cosechadoras, sembradoras y vehículos todo terreno (el célebre Land Rover), o la de Oleometalgráfica del Sur, especializada en envases de conservas y donde se jacta la locución en exponer el dato ocupacional de la mujer trabajadora, que llega al setenta por ciento. Otro guiño a la modernidad del Régimen y a su apuesta por la "paz social" al dar ocupación al excedente de mano de obra que ya comenzaba a salir de las minas (imagen 7).

A estas alturas está clara la visualización de nuevos criterios ideológicos, especialmente desde que comienzan a aplicarse las medidas del Plan Nacional de Estabilización Económica:

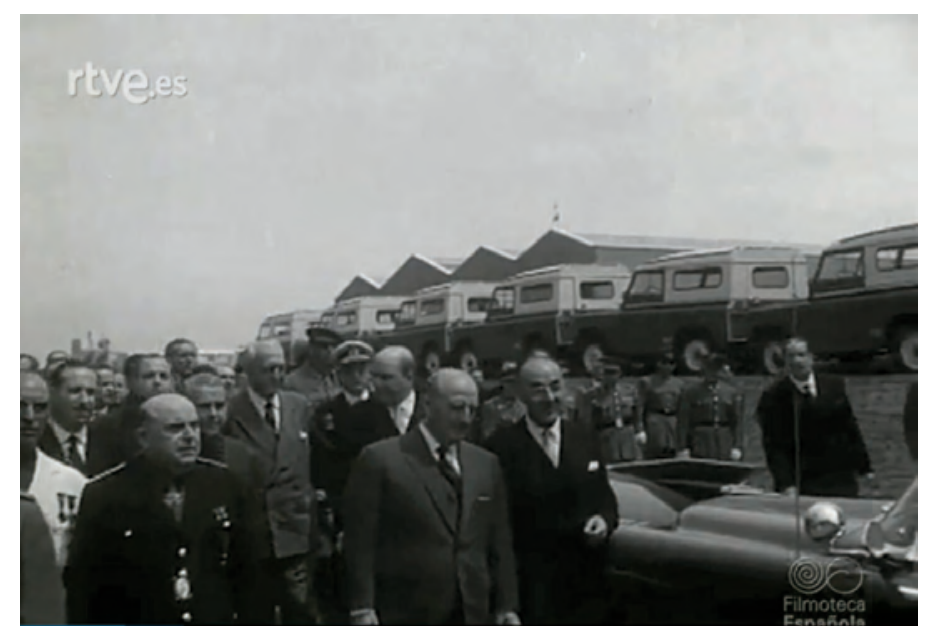

Imagen 7. Franco visita la metalurgia Santana en Linares (noticiario 956-A, 1961). 
"Un último ámbito estaría constituido por aquellos lugares ya establecidos, de los que el franquismo se apropia para que queden asociados a su obra. Son esos sitios (fábricas, ferias, campamentos, edificaciones, residencias,..) que reiteradamente se convirtieron en espacios de representación, vía inauguración o visita oficial. La mayoría de ellos estarían conectados a las transformaciones industriales, al desarrollo técnico, la creación o reconstrucción de infraestructuras. Todos estos elementos configurarán el nuevo referente del proyecto social franquista... sustituirán progresivamente como estandartes del ideal de España al esfuerzo, la laboriosidad y el tesón del trabajador (señas de identidad de los valores fundacionales del Régimen en los años 40). Estas nuevas mitologías se trasladarán, como decimos, a nuevos espacios" (Tranche y Sánchez-Biosca, 2006: 232).

De esa estrategia presume Franco ante el pueblo de Linares, desde el balcón del ayuntamiento, estableciéndolo como modelo para el progreso económico de otras provincias españolas. No es inocente que el noticiario acabe así, en una plaza abarrotada de gente. La segunda parte de ese viaje se observa en el noticiario 956B y resulta una continuación evidente, formal e ideológica, con el discurso anterior. Continúa vestido de civil inaugurando una fábrica de conservas en Mengíbar (Sacove), capaz de envasar 15000 toneladas de tomate al año, para posteriormente seguir hacia Marmolejo con su numerosa comitiva de vehículos. Aquí aparece inaugurando la Granja Escuela de Formación Profesional Agraria "Virgen de la Cabeza", realizando un recorrido por el Centro en el que se nos muestran las diversas dependencias (aulas con laboratorio, comedor o sala de juegos). Se hace hincapié en la importancia de la formación técnica de los obreros, que aparecen de hecho en una demostración práctica de fumigación, pero también presenta al centro como un modelo arquitectónico establecido por la Organización Sindical, cuyos escudos lucen a ambos lados del balcón en la fachada principal desde la que el Caudillo se dirige a los asistentes. La llegada a Jaén capital por parte de la comitiva que acompaña a Franco concluye el primer día de su estancia en la provincia. Teniendo en cuenta los principios de jerarquía y centralización políticas característicos del Régimen, la capital debía aparecer como cabeza rectora de todo el territorio y, en consecuencia, aquí es donde se despliega el mayor aparato representativo. Éste se manifiesta en la arquitectura efímera dispuesta a la entrada de la otrora plaza de José Antonio desde la calle Virgen de la Capilla, con una gran estructura adintelada de carácter moderno flanqueada por dos altos pilares asimétricos y decrecientes de altura. Sobre el dintel en letras mayúsculas se lee FRANCO y en la parte baja de ambos extremos se disponen los escudos de la Falange y del Carlismo. El flamante Rolls Royce desfila desde aquí, acompañado por un largo reguero de vehículos, hasta la plaza del Ayuntamiento, en cuyo balcón principal Franco arenga a la ciudadanía, llegada de todos los lugares de la provincia. Es precisamente la capital del Santo Reino el lugar al que Franco reserva su discurso político por excelencia, la celebración en 1961 del 25 aniversario del inicio de la Guerra Civil, encomendándose a Dios (de nuevo la tradición), por haber emprendido el camino de la verdad “...para salvar los valores espirituales de nuestros hogares y familias”. Una imagen crepuscular que coincide en el noticiario con la llegada de la noche.

El segundo día de su estancia en la provincia la realiza Franco vestido de militar, iniciándose con la inauguración del Centro de Formación Profesional Acelerada, acompañado por los ministros Carrero Blanco y José Solís, éste último Secretario General del Movimiento y Delegado Nacional de la Organización Sindical, organismo promotor del centro, al igual que el de Marmolejo. La narración del acontecimiento deja bien clara la intencionalidad del servicio puesto en uso para la población jiennense:

"Durante su estancia en la ciudad inaugura el Centro de Formación Profesional Acelerada, que en cursos de seis meses prepara a los obreros en diecisiete actividades laborales. 
Tras el Ministro Secretario General del Movimiento explica Franco cómo hemos de avanzar y progresar sin destruir el orden económico. Seguidamente recorre la Escuela y conversa con los que en ella trabajan y dejaron de ser braceros para transformarse en especialistas y adquirir conocimientos que mejoran su condición social"

La visita a Jaén continuó con un desfile de carrozas motorizadas por la Carrera, decoradas por las diferentes empresas que habían sido beneficiadas por la financiación del Plan Jaén, y destacando las dos nuevas que se implantaron en Linares (Santana y Oleometalgráfica del Sur), así como otra muy espectacular con mineros barrenando una gran roca. Franco asiste al desfile desde una tribuna dispuesta en la parte alta de la calle de la que no se dan imágenes muy representativas, siendo visible tan sólo el lema de VIVA FRANCO que la corona, con una grafía muy moderna, y la aparición del célebre vítor en uno de los laterales. Sí resulta llamativo el gran retrato con la efigie del dictador desplegado en uno de los edificios de la plaza de San Francisco, abarrotada para escuchar el último saludo de Franco desde el balcón principal, de nuevo, del Palacio de la Diputación Provincial.

Continuando con este discurso de jerarquización escenográfica, es significativo que las celebraciones "menores" es decir, aquellas que no cuentan con la presencia del Caudillo o de algunos de sus ministros, resultan efectuadas con menor aparato. Eso sucede, por ejemplo, en el noticiario $1005 \mathrm{C}$ que relata la conmemoración del final de la guerra por parte de los excombatientes el 1 de abril de 1962. Aunque la concentración resulta multitudinaria, sólo cuenta con la presencia del Alcalde de Jaén y del Gobernador Civil de la provincia, quienes se dirigen a los asistentes desde un estrado erigido en la puerta de la sede del Ministerio de Hacienda en la antigua plaza de José Antonio. Se caracteriza por su sencillez, pues tan sólo está rodeado en su antepecho por una bandera de España de la que cuelgan algunos pendones con el vítor franquista. Sólo dispone como excepcionalidad de un respaldo floreado en el que se inscribe una cruz, símbolo no demasiado común en el repertorio visual del propagandismo franquista. Sí llama la atención la aparición de dos lugares no demasiado corrientes en las referencias urbanas del imaginario ideológico en Jaén, precisamente por estar lejos de los dos centros de poder por excelencia como son el Ayuntamiento o el Palacio de la Diputación. Me refiero en primer lugar al paseo de la Alameda, donde estaba ubicada la Cruz de los Caídos y se celebra una misa, y en segundo lugar al paseo de la Estación, entonces avenida del Generalísimo, por donde desciende desde la plaza de José Antonio un masivo desfile. Es abanderado por jóvenes de la OJE (Organización Juvenil Española), movimiento fundado en 1960 dependiente del Frente de Juventudes y de la Secretaría General del Movimiento, que hace su presentación por primera vez en la capital en todos sus grados, desde flechas a cadetes, luciendo en sus camisas y petos las siglas y el escudo representativo. La grandilocuencia del lenguaje en la locución del narrador los presenta como huestes herederas de los excombatientes, pues "....aunque por la edad no pudieron luchar en los campos de batalla, conocen las huellas de sus padres". Resulta significativo que este discurso ideológico se visualice a través de la avenida del Generalísimo, fruto en ese momento de una profunda remodelación arquitectónica consistente en el derribo de los antiguos palacetes burgueses y su sustitución por modernas torres de pisos o edificios que albergan nuevos servicios (es el caso del Cine Asuán, que aparece en construcción). ¿Fusión ideológico-arquitectónico-visual? Es difícil llegar a concluir si los guionistas del NO-DO llegaban a hilar tan fino, pero es cierto que a partir de entonces la citada avenida del Generalísimo se convierte ya en un referente visual de los noticiarios sobre Jaén (imagen 8).

Un año más tarde, de hecho, el protagonismo se lo lleva un edificio situado en esta vía, el de la Confederación Nacional de Sindicatos (CNS), al que acude el ministro Secretario General del Movimiento, José Solís, para presidir una reunión del Consejo Económico Sindical e inaugurar la emisora sindical "La voz de Jaén", cuya sede iba a disponerse allí. Nos referimos al noticiario 1066 b del año 1963, que inicia su información con un plano fijo desde el cerro de Santa Catalina, para pasar seguidamente a una imagen de la fachada 


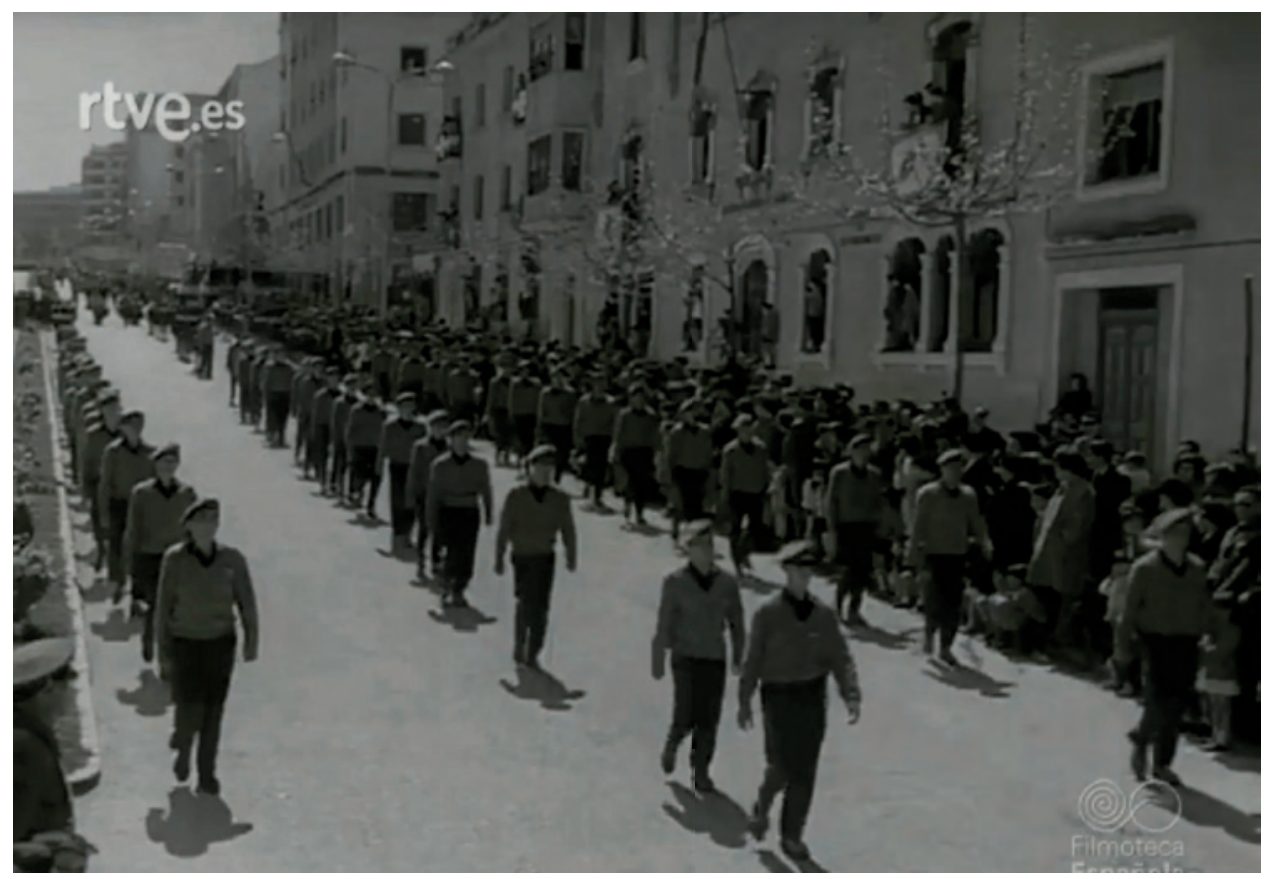

Imagen 8.- Jóvenes de la OJE desfilan por la avenida del Generalísimo en Jaén (noticiario 1005 C, 1962).

del edificio, engalanada con las tres banderas tradicionales del Régimen. A diferencia de la modernidad del Centro de Formación Profesional Acelerada inaugurado el año anterior, la sede sindical se nos presenta como el contrapunto que ofrecía la otra cara constructiva del Régimen, con el historicismo propio de los primeros años del Franquismo. Aunque no se cita, el edificio obedece a un proyecto del año 1948 del arquitecto Juan Piqueras Menéndez, pero curiosamente en los años sesenta ya se estaba trabajando en la realización de una obra totalmente nueva para la sede de la CNS, un rascacielos de nuevo cuño estético, plenamente racionalista, encargado al arquitecto José Jiménez Jimena en la misma avenida del Generalísimo, esquina con la plaza de las Batallas. Nuevos tiempos para una vieja institución, casi como la manera en que se nos presenta el ministro Solís en el noticiario, vestido de civil, cuando era bien conocida su imagen con la indumentaria falangista. Tan moderno como esa locutora que realiza su trabajo luciendo una permanente muy lacada, entre sus compañeros y la moderna electrónica de la emisora, inaugurada por cierto por algún que otro mitrado que, ni se nombra, ni aparece en primer plano. El giro de los tocadiscos adquiere mayor importancia visual e informativa.

Casi diez años pasarán para que Jaén capital vuelva a aparecer en el NO-DO, más concretamente en el noticiario 1596-A del año 1973, el primero realizado como página en color y con diferente dinámica visual y perspectiva ideológica. Se sigue iniciando como casi gran parte de los informativos relativos a la ciudad, con una panorámica desde el cerro de Santa Catalina, pero ahora nos introduce en ella con un rápido zoom hacia la plaza de Santa María, donde el locutor se recrea en datos muy precisos sobre la Historia y el Arte de la Catedral, nombrando sus estilos, citando a su constructor, Andrés de Vandelvira, e incluso dando precisiones iconográficas sobre la imaginería de la fachada. Estamos ante una especie de publireportaje con un interés de promoción turística, lo cual es una constante en los noticiarios e 
imágenes del NO-DO en esta época final de su singladura, como lo atestiguan los realizados sobre los paradores de Cazorla y Úbeda, la Romería de la Virgen de la Cabeza o Baeza monumental. Se ameniza además con música actual, que ofrece al espectador no sólo el valor y la belleza del peso histórico de la ciudad de Jaén, sino el dinamismo de una urbe moderna visible en una imagen del recién inaugurado rascacielos que alberga la Confederación Nacional de Sindicatos (José Jiménez Jimena, 1965), vista desde la plaza de las Batallas. La avenida del Generalísimo se ha convertido ya en la referencia de la nueva urbanización, con su amplio trazado por donde transitan los autobuses y las personas, algunas luciendo atrevidas minifaldas, y se visibilizan los luminosos de comercios representativos, como el de Galerías Preciados. Un dinámico zoom hacia atrás recorre la citada arteria hasta la plaza de José Antonio y en ese momento regresa de nuevo el referente histórico que nos lleva al Castillo de Santa Catalina. Se redondea el discurso del noticiario, mostrándonos imágenes del moderno Parador Nacional de Turismo ubicado allí (José Luis Picardo Castellón, 19651972), que según el narrador “....armoniza modernas comodidades con grandezas pretéritas". Finaliza con una perspectiva exterior del patio de armas del Castillo en travelling hacia las montañas circundantes y, desde allí, hasta el cielo. La guitarra flamenca, que no ha dejado de sonar desde el momento en que aparece el Parador, concluye el reportaje.

Casi dos años después la imagen de Jaén vuelve a ser recurrente como urbe moderna en el noticiario 1688-A, que muestra la inauguración del complejo deportivo de la Salobreja (Luis Berges Roldán), donde se celebra la final de la Copa de España de Baloncesto (1975). Llama la atención una narración parca en palabras, nada politizada, que se limita a la retransmisión del partido entre el Real Madrid y el Estudiantes. Pabellón a reventar, ocupado por aficionados desplazados desde toda España, y cámara rápida que se recrea en las canastas más significativas. Publicidad estática alrededor del campo (Mapfre Vida, El Corte Inglés, Corberó, Wrangler o Schweppes), y un público entusiasta que es enfocado de vez en cuando. La pretendida "funcionalidad" del extrarradio urbano iba completando el nivel de sus servicios, en este caso a lo largo de la carretera de Granada, aunque con evidente tardanza cronológica.

Cabe destacar en estos últimos años de los reportajes del NO-DO la casi exclusividad de la capital de la provincia y, de hecho, ese mismo año de 1975 Jaén vuelve a acaparar la atención en el noticiario 1715-A, que se titula "Toros". Es otra página en color que informa sobre el tradicional cierre de la temporada taurina en España durante la celebración de las fiestas de San Lucas. La modernidad aquí aparece de manera evidente en el enfoque de dos cámaras de TVE captando el evento dentro del ruedo y quizás la elección del tema tenga algo que ver con la retransmisión unos años atrás, concretamente el 13 de junio de 1971, de la conocida como "Corrida del siglo". El impacto de la noticia entonces a nivel nacional, dio gran fama al coso taurino de Jaén, pues se hizo vía satélite y en color por la televisión americana ${ }^{11}$. Por lo demás, el discurso visual del noticiario es el característico de los años setenta, con la presentación de una urbe moderna que ahora nos muestra una nueva centralidad urbana, el parque de la Victoria, con nuevos edificios para servicios emergentes, como el Hotel Condestable Iranzo, o torres de pisos, como la del arquitecto López Rivera en la misma plaza de las Batallas. También se recrea la cámara en la fachada exterior del edificio de la Plaza de Toros (Antonio M ${ }^{a}$ Sánchez, 1958), del que interesa también esa imagen de actualidad, contrastada con otras edificaciones del pasado histórico. Por lo demás el resto del noticiario resulta ser el resumen de una retransmisión taurina que va desde el paseíllo de los toreros y cuadrillas, hasta el visionado de los mejores faenas, incluida la presencia de un rejoneador, Ángel Peralta. Se va alternando el desarrollo de la noticia con planos del

11 Participaron los diestros Santiago Martín “el Viti”, Manuel Benítez “el Cordobés” y José Fuentes, y tuvo gran difusión a nivel nacional, retransmitida en blanco y negro: http://hemeroteca.abc.es/nav/Navigate.exe/hemeroteca/madrid/abc/1971/06/15/079.html 
público, que no llena la plaza, algún que otro mantón de Manila o traje de faralaes, y música de fondo donde se escucha un pasodoble. La narración visual concluye con una panorámica de la ciudad desde el Castillo, recurso que solía ponerse hasta entonces al principio de los noticiarios, donde se pueden observar ya nuevos equipamientos, como los del polígono industrial. La imagen televisiva, a la vez que la ausencia cada vez mayor de los mensaje políticos, el mismo año precisamente en que fallece Francisco Franco (el noticiario tiene fecha de 8 de diciembre de 1975, tres semanas después de su muerte), influyeron en el abandono paulatino del sentido originario del NO-DO y en su inevitable desaparición final.

\section{Bibliografía}

BERMEJO SÁNCHEZ, B. (1991). “La Vicesecretaría de Educación Popular (1941-1945): un «ministerio» de la propaganda en manos de Falange”. Espacio, tiempo y forma, S.V. $\mathrm{H}^{\mathrm{a}}$ Contemporánea. t. IV. Madrid: Universidad Nacional de Educación a Distancia, 73-96.

CASUSO QUESADA, R. (2016). "El proyecto de Columnas cineparlantes y publisonoras en Andújar (1941). Un hito en la labor propagandística del Franquismo en España”. En Andújar. Estudios en recuerdo de Enrique Toral y Manuel Urbano. Andújar: Ayuntamiento, 69-82.

CASUSO QUESADA, R. (2012). "El proceso de liquidación de las casas-cueva en Jódar en el contexto de la vivienda social del primer franquismo en Andalucía". Gazeta de Antropología, 28 (II). Granada: Universidad, 1-17.

FANDIÑO PÉREZ, R. G. (2009). La Rioja al alcance de todos los españoles. NO-DO y la construcción de un discurso sobre la provincia. Logroño: Gobierno de La Rioja \& Instituto de Estudios Riojanos.

NAVARRETE-GALIANO, R. (2003). Huelva en el NO-DO. Sevilla: Fundación El Monte.

QUESADA GARCÍA, S. \& CASUSO QUESADA, R. (2006). La estación de autobuses de Jaén: una topografía de su arquitectura. Sevilla: Consejería de Cultura de la Junta de Andalucía.

UREÑA PORTERO, G. (1979). Arquitectura y urbanística civil y militar en el período de la autarquía (1936-1945). Madrid: Istmo.

TRANCHE, R. \& SÁNCHEZ-BIOSCA, V (2006). NO-DO. El tiempo y la memoria. Madrid: Cátedra / Filmoteca Española. 